\title{
A atuação \\ do psícólogo \\ na área cognitiva: reflexões e \\ questionamentos
}

\author{
Alina Galväo Spinlllo e \\ António Roazzi \\ Oxford University \\ Department of Experimental Psychology
}

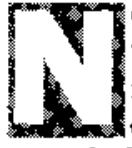

intuito de caracterizar o papel do psicólogo cognitivo no espaço da Psicologia como trabalho abordará alguns aspectos referentes à relaçào da psicologia cognitiva dentro da própria Psicologia, refletindo-se sobre a atuaçào do psicólogo cognitivo enquanto cientista e profissional, procurando-se diferenciar o seu papel frente à atuaçào de profissionais de areas afins.

Alguns aspectos históricos, relativos ao surgimento da psicologia cognitiva, serào considerados para melhor caracterizar a maneira como esta foi definida e como posicionou-se frente a alguns pressupostos teóricos e metodológicos vigentes no periodo posterior à II Guerra Mundial. De fato, nas últimas décadas o estudo dos processos cognitivos tem se expandido rapidamente e,do ponto de vista teórico, tem se mostrado uma abordagem relevante para a explicaçào do comportamento humano, trazendo à tona aspectos centrais da psicologia.

Os aspectos aqui ressaltados visam, mais do que respostas, gerar reflexỏes e questionamentos, contribuindo para uma maior compreensảo da área cognitiva dentro da psicologia como um todo.

\section{Considerações Históricas: do Behaviourismo ao Cognitivismo \\ A psicologia cognitiva, assim como tambèm outras áreas da psico- logia, toi influenciada negativamente por uma série de pressuposiçoes res- tritivas definidas como positivistas,}

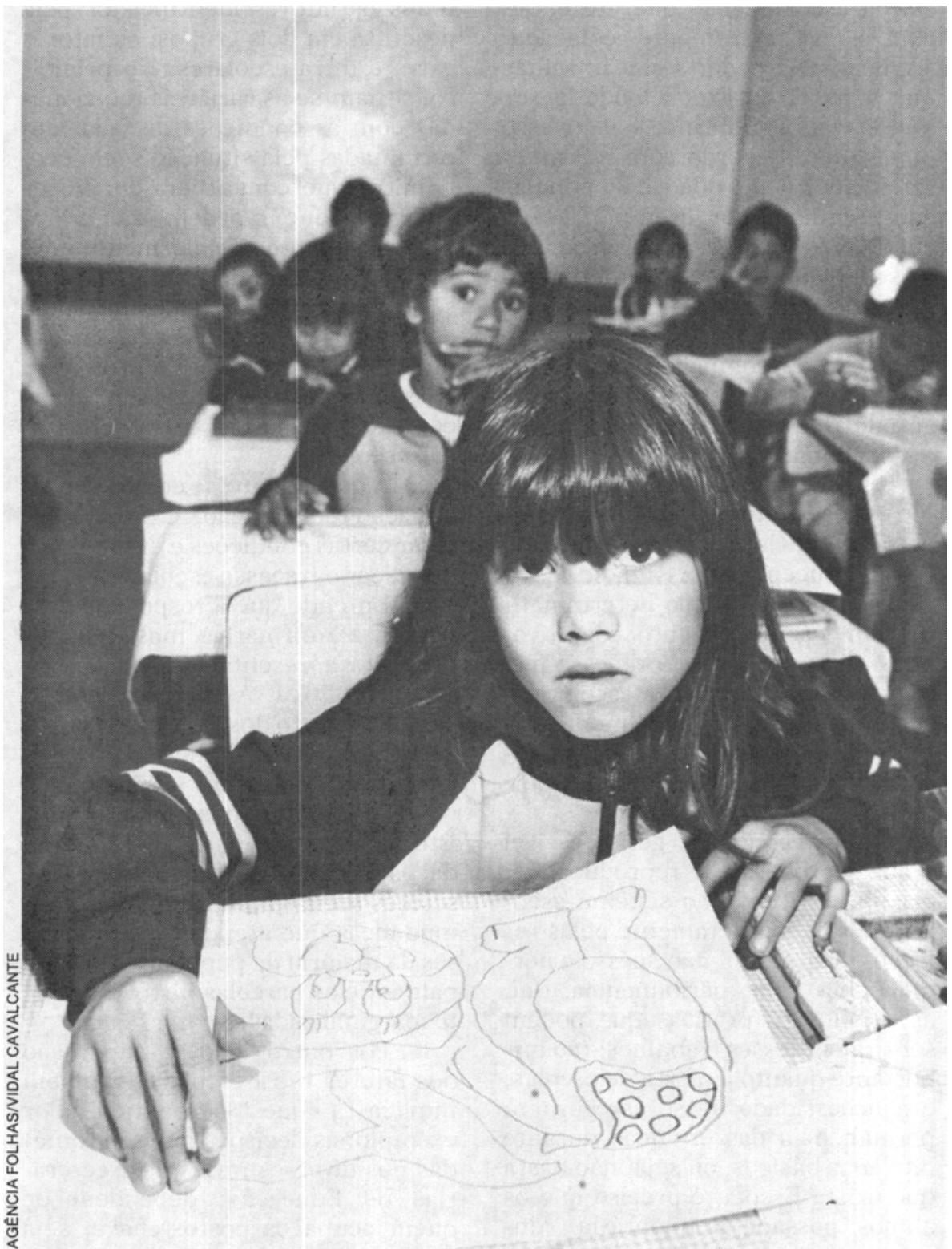


como afirmado por Parisi et alii (13). Estas pressuposiçōes especificavam que o objeto de estudo da psicologia seria exclusivamente o comportamento observaivel e que a maneira correta de se efetuar investigacóes sobre este objeto seria através da determinaçào da relaçào estímulo-resposta, isto é, atravès da pesquisa de correlaçóes entre as condiçoes (em geral externas ao individuo) e as respostas emitidas pelo individuo frente a estas condiçóes. Dentro deste enfoque, o estudo do comportamento limitava-se à identificaçào das correlacoos existentes entre as variaveis em funçāo do contexto experimental e as respostas observáveis nos comporta. mentos produzidos pelo indivíduo. $O$ que acontece no interior do individuo era de fato irrelevante e eliminado da investigaçào, dado que nāo se poderia controlar adequadamente tais aspectos.

Estas pressuposiçoes foram rè. jeitadas pela psicologia eognitiva, que procurou superar este modelo reducionista e mecanicista do comportamento, partindo do pressuposto de que nào é possivel tratar a relaçào entre o estimulo e a resposta como simples e linear. Nesta abordagem a atençao recai sobre as estruturas, os processos e os mecanismos que constituem a mente do individuo, esta mesma mente que tinha sido descar. tada pelos behaviouristas e definida de forma metafórica como "Caixa Preta".

Esta recusa em aceitar o mode. to $\mathrm{E}-\mathrm{R}$, pregado pelos behaviouristas, partiu da evidència de que no individuo existem mecanismos e processos que irào entrar em açào no momento da elicitaçào das respostas, independentemente do nivel de simplicidade ou elaboraçào destas. Como sublinhado por Caramelli $(2 ; 3)$, no decorrer da investigaçào psicológica é impossivel abstrair-se as condiçoes do funcionamento complexo do individuo que, na sua maneira de operar, influencia nào só a resposta, ou seja, o produto final do comportamento, mas também possui um efeito retroativo ao nivel da intensidade e qualidade do estimulo.

Desta forma, a psicologia cogni. tiva considera o modelo linear ER limitante, insuficiente e conseq"uentemente inadequaddo para explicar o comportamento humano, procuran. do substitui-lo por um esquema mais complexo e elaborado que considera de forma circular esta relaçào diádica entre organismo e estimulos (Nota A). O organismo tem papel relevante e ativo, um sistema capaz de elaboraçoes complexas, tais como: efetuar escolhas dentre os elementos relevantes de uma dada situaçao, utilizar estratégias alternativas, armazenar seletivamente informaçoes, operar transformaçōes sobre os elementos de forma a elaborá-los apropriadamente, operando os resultados dessas elaboraçóes e nào apenas operacooes ligadas e determinadas, aprioristicamente, pelos estímulos de entrada (6).

De acordo com este enfoque, a tarefa do psicólogo cognitivo é descobrir leis que estabeleçam conexōes entre o comportamento e a variedade de aspectos e elementos com os quais o comportamento esta relacionado, prosurando encarar o problema de forma mais abrangente. No plano epistemológico e metodológico esta tareía inclui a elaboração de modelos teóricos das estruturas dos processos e dos mecanismos que constituem a vida mental do indivíduo. $O$ estudo das condiçòes que influenciam o comportamento se torna, assim, apenas um meio para alcançar este fim. Em outras palavras, a psicologia tem que tentar ir alem do simples estabe. cimento de certos comportamentos que se manifestam em certas condicòes, mas procurar elaborar modelos explicativos dos mecanismos mais amplos que operam na mente do sujeito, com base nos quais o individuo manifesta aquele comportamento naquelas condiçōes (13).

Neisser (12), a partir do paralelismo instituido entre organismo humano e computador, precisa que a tarefa do psicólogo cognitivo, que procura entender os mecanismos e processos na aquisiça e desenvolvi-' mento do conhecimento, é análogo àquele do técnico em computaçào que procura descobrir como foi programado um computador. Por exemplo, no caso de um programa para ar. mazenar informaçóes, o técnico tem de descobrir através de quais procedimentos é alcançado este objetivo. A ele nào interessa de forma alguma se o computador armazena a informacào em "floppy disk", em "hard disk" ou em "fita magnética", o que se torna de fato importante è entender o programa e não o computador em si. O programa é um conjunto de asserçòes expressas em uma linguagem particular que constitui as intrucóes que o computador tem de exe- cutar para processar uma série de símbolos do tipo "se o estimulo for do tipo $\mathrm{X}$, executar ' $\mathrm{X}$ ' operaçóes, mas se o estímulo for do Tipo $Y$, executar ' $\mathrm{Y}$ ' operacooes... processar as combinaçōes dos vários inputs desta forma e ... etc. Assim, para Neisser, o psicológo cognitivo procura alcançar explicaçóes deste tipo para todos os mecanismos, objetivando descobrir como a informaçào é elaborada no in. terior do organismo humano.

Enfim, a psicologia cognitiva nāo está preocupada com as elaboraçóes das condiçóes de estimulaçāo que produzem um determinado com. portamento, nem em indicar sim. plesmente com que probabilidade é possivel elicitar uma certa resposta a partir de uma certa estimulaçào. Pelo contrário, procura especificar os mecanismos e processos mentais no organismo e propor modelos que indiquem as fases dos processos mentais e as funcòes desenvolvidas por estas fases.

Em seguida a essas considera. cooes históricas, faz-se recessário apresentar o que entendemos por psicologia cognitiva, a relaçào desta com outras áreas da psicologia e com areas afins, comparando-se, ainda, diferentes perspectivas sobre a psicolo. gia cognitiva no Brasil e em outros paises.

\section{A Psicologla Cognitiva: Objeto e forma de Investigação}

A Psicologia é uma ciência que está presente em diversas áreas: social, afetivo-emocional, patológica, educacional, nas relaçōes de trabalho e na área cognitiva. A maioria das pessoas, principalmente aquelas que nào estāo diretamente ligadas à Psicologia, acredita que os psicólogos trabalham apenas como terapeutas e que provavelmente possuem algum "dom especial" para conhecer profundamente as pessoas. No entanto, sabemos que há várias áreas na ciência psicológica e que uma delas é a cognitiva, ponto de reflexảo neste trabalho.

\section{O objeto de investigação do psicólogo cognitivo}

O psicólogo cognitivo estuda as bases do conhecimento humano; mais precisamente, estuda os meios pelos quais o individuo aleanẹ um conhecimento organizado do mundo em categorias, como também a maneira pela qual este conhecimento é utilizado para direcionar e planejar 
açóes sobre o ambiente. Este conhecimento categorizado torna-se indispensavel como instrumento de compreensào e atuaçảo sobre a realidade.

Bruner, Goodnow e. Austin (1:1) afirmam que o mundo da experiência de cada individuo é composto por um numero enorme de diferentes objetos, eventos, pessoas e impressỏes capazes de serem discriminados e categorizados de forma organizada pelo individuo. Se acaso os individuos nảo apresentassem esta capacidade de registrar as diferenças e categorizá-las em um mundo organizado, provavelmente seriam subjugados pela complexidade do ambiente.

Assim, o psicólogo cognitivo estuda nào só a forma como as informaçóes externas sào extraidas, mas, especialmente, como estas informaçöes sāo conceptualizadas e organizadas internamente, para então serem utilizadas de maneira eficaz. Podemos acrescentar, ainda, que está preocupado com aspectos que implicam elaboraçóes internas, partíndo do pressupostó de que a resposta dada à de . terminada situaçào-estimulo sofreu algum tipo de elaboraçào dentro do individuo,e que esta elaboraçào nảo depende apenas do estimulo externo apresentado, mas de processos mentais internos presentes na mente do individuo em um momento determinado do seu desenvolvimento e em funçāo de elaboraçōes anteriores que tenham sido efetuadas.

Utilizando uma terminologia mais tradicional, o psicólogo cognitivo estuda aspectos da atividade cognitiva representados pela percepçào, memória, imagem mental, pensamento, raciocinio, aprendizagem etc. Em outras palavras, interessa-se pelos mecanismos mentais que agem quando se percebe, se memoriza, se elabora mentalmente um dado objeto, quando se aprende, etc. Estes conteúdos da consciência sào considerados como o produto de uma série de elaboraçôes e operaçōes conduzidas sobre e a partir de informaçôes e que se referem ao conhecimento.

\section{A manelra de estudar do paicólogo cognitivo}

Vimos que o interesse da psico. logia cognitiva recai sobre a natureza do conhecimento, sobre as estruturas e processos pelos quais este é adquirido e a maneira como se desenvolve. Este interesse se traduz em estudos experimentais, pois de fato nào estuda as bases do conhecimento partindo de especulações, mas através do estudo empirico, como qualquer outro cientista.

Para tal, a observaçảo torna-se um instrumento de fundamental im. portância. Segundo Carraher, (4), aprender a observar em psicologia é algo mais dificil do que se pensa e exige que tentemos encontrar os significados do comportamento em observaçào, procurando abandonar nossa perspectiva particular e descobrir a prespectiva de mundo do sujeito em observação, seu modo de operar so. bre $o$ ambiente e os significados que ele atribui às pessoas e às coisas. Entretanto, a observaçào em si mesma, por mais fidedigna que seja, nào pode ser encarada isoladamente, sendo necessário estabelecer uma relaçào entre observar, refletir e compreender.

Estabelecida esta relaçảo, o psicólogo cognitivo levanta hipóteses, testando-as, buscando compreender os fenômenos que se propõe a investigar. Neste sentido, seu trabalho se assemelha em muito ao trabalho do cientista no que se refere a investigaçào dos aspectos do conhecimento, podendo muitas vezes utilizar-se de métodos de investigaçào como o método clínico, por exemplo, (Nota D) ou métodos derivados de outras áreas como a Antropologia.

\section{A Peicologla Cognitiva e outras áreas da Psicologia}

Analisando-se o papel da psicologia cognitiva cabe refletirmos sobre o status desta dentro da própria Psicologia. Considerando-se a ênfase historicamente dada à psicologja clinica, durante muito tempo passou-se a conceber o papel do psicólogo relacionado apenas ao cuidado e tratamento de problemas pessoais ligados aos aspectos afetivo-emocionais. Sem dúvida esta é uma área relevante da Psicologia, como o sào igualmente as demais áreas.

Colocando-se em perspectiva a psicologia clinica e a psicologia cogni. tiva, o que podemos notar no mo. mento è uma setorialização no dominio do conhecimento. $O$ psicólogo cognitivo pouco sabe acerca de aspectos afetivo-emocionais, informaçỏes estas que mesmo năo sendo relevantes ao nivel de sua produçào cientifica enquanto pesquisador, seriam importantes ao nivel prático. $\mathrm{O}$ psicólogo clínico, por sua vez, descar ta de sua próxis informaçóes sobre o desenvolvimento cognitivo.
Tomemos como exemplo hipotético o caso de uma criança que apresenta dificuldades de aprendizagem. Na visào do psicólogo cognitivo, estas dificuldades poderāo ser atri. buidas aprioristicamente a problemas no âmbito do desenvolvimento cog̣nitivo. Na visào do psicólogo clinico estas mesmas dificuldades serào sem dúvida atribuidas a problemas pessoais vividos pela criança. Tanto por um como por outro profissional, hipóteses alternativas são de imediato descartadas de suas investigaçōes sobre o caso.

Nào se deseja afirmar aqui que caberia ao psicólogo cognitivo tratar das dificuldades afetivo-emocionais da crianca em questăo, ou que o psicólogo clínico, especialista em dificuldades de ordem afetivo-emocional, deveria desenvolver algum tipo de terapia cognitiva com a mesma. Dai a importância das competências especializadas. Mas, quando o que entra em jogo sāo as competências setorializadas, informaçōes relevantes nảo sảo consideradas e hipoteses sào a priori descartadas do repertório de possiveis respostas ao caso em estudo. (Nota B)

Mas alèm do problema da setorializaçāo do conhecimento dentro da própria psicologia, a psicologia cognitiva se depara com o problema da incompreensão do que vem a ser estudos cognitivos e estudos piagetianos, parecendo ser necessário uma reflexào sobre esta questào.

\section{Controvérsias: são psicólogo cognitivo e psicólogo plagetiano sinónimos?}

$\mathrm{O}$ método clinico foi o método de estudo utilizado por Piaget em suas investigaçōes e $\hat{e}$ um método bastante usado na pesquisa cognitiva, embora nào seja o único. Talvez te. nha sido deste fato - utilização do método clínico como técnica de investigacào - a errônea idéia de que psicólogo cognitivo e piagetiano são sinônimos. E evidente que nào se pode negar a inestimável contribuiçào e influência da teoria piagetiana na psi. cologia cognitiva, mas nem todo psicólogo cognitivo è necessariamente piagetiano. Poderiamos dizer que Piaget está para a psicologia cognitiva assim como Freud está para a psicologia clinica. Da mesma forma que nenhum profissional $\mathrm{da}$ área clinica pode ignorar a obra de Freud, mesmo que nảo seja considerado um freudiano; nenhum psicólogo cognitivo ou do 


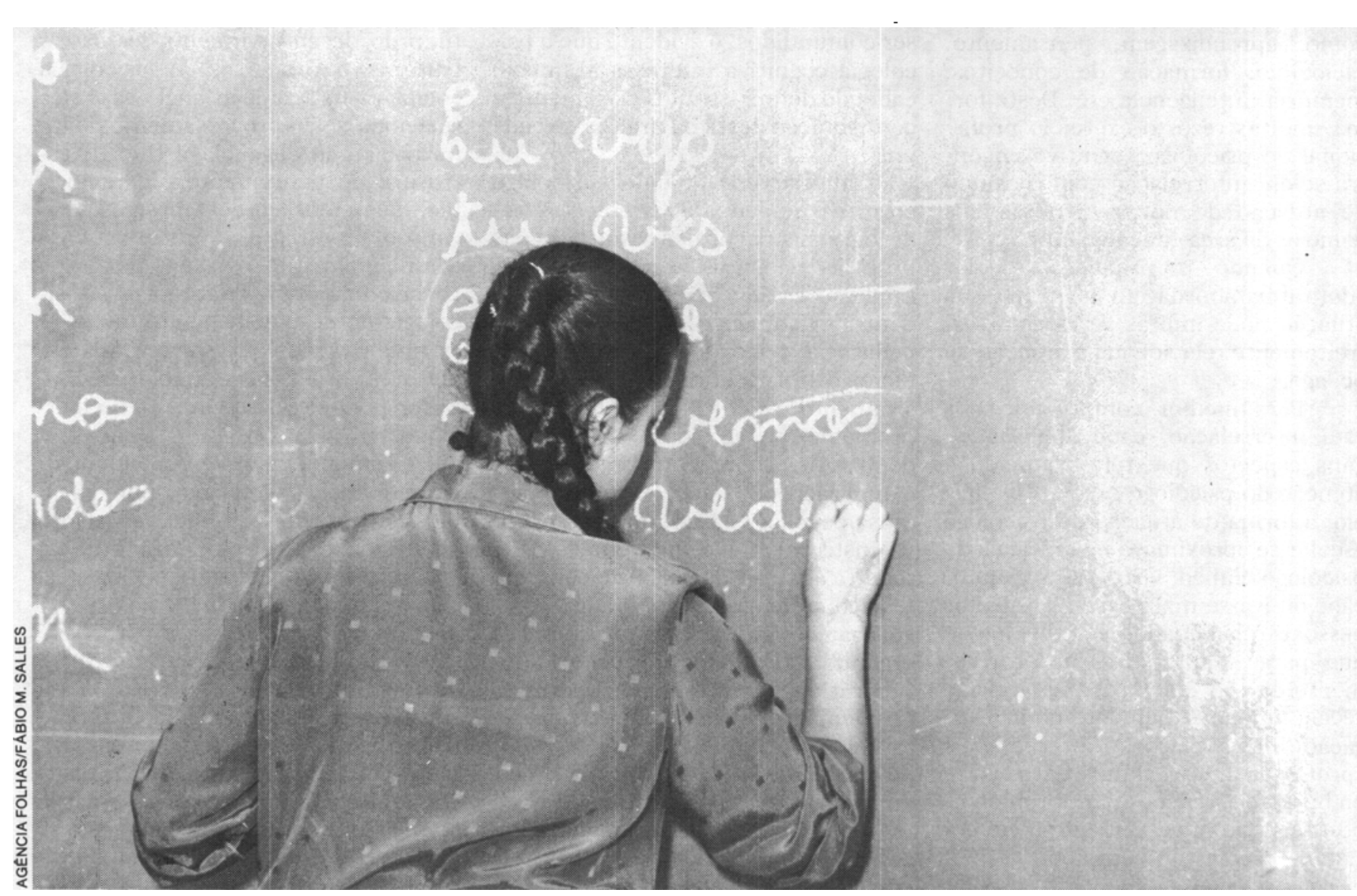

descnvolvimento, de modo mais amplo, pode ignorar a obra de Piaget, mesmo que nảo seja piagetiano. Da mesma forma que na psicologia clínica existem diferentes métodos de atuação terapêutica desta àrea; na psicologia cognitiva também existem diferentes métodos. A utilizaçào do método clinico por si ou de tarefas piagetianas, nào garante que o psicólogo seja necessariamente adepto incondicional da teoria de Piaget.

Tal fato tem gerado muita incompreensảo nảo só entre leigos, como por parte de profissionais de psicologia. Um exemplo desta incompreensảo pode ser citado quando da entrevista realizada pela revista $P$ sicologia Ciència e Profíssáo (Ano 7 $\mathrm{N}^{9} 1 / 87$ ) com os professores e pes. quisadores David W. Carraher e Analucia $\mathrm{D}$. Schliemann, da Universidade Federal de Pernambuco. Na sequência da discussảo do tema a pergunta formulada pelo entrevistador "Como os estudos piagetianos brasileiros podem orientar politicas educacionais?" (p.27) reflete em parte esta incompreensáo. Nào são os estudos piagetianos que podem contribuir para a compreensảo do fracasso escolar, mas estudos sobre a maneira pela qual a criança aprende, como afirmado pelos entrevistados ao modificarem a pergunta antes de respondê-la. Neste caso, os estudos sobre cogniçào foram tomados como sinônimos de estudos dentro de uma abordagem piagetiana.

Nảo se deve considerar piagetianos os estudiosos que, como Piaget, se preocupar com o desenvolvimento do conhecimento e que adotam uma perspectiva construtivista. $O$ fato de partir-se de pressupostos adotados por esta ou aquela teoria não significa ser seguidor da teoria. Algumas vezes os estudos gerados a partir de um dado enfoque teórico contribuem para uma revisảo da própria teoria que os gerou. A literatura apresenta diversos estudos em que sảo utilizadas tarefas piagetianas e um referencial teórico diferente da abordagem de Piaget. Estudos como os de Roazzi (15) sobre inclusào de classes, de Hughes, e Donaldson (7) sobre egocentrismo e dezenas de estudos sobre conservaçảo de quantidades, dentre eles os de Rose e Blanck (16), Light, Buckingam e Robbins (8), MacGarrigle e Donaldson (11), Roazzi e Dias (15), os quais apresentam resultados que levam a uma reanálise de alguns pontos da teoria de Piaget, mesmo utilizando as tarefas por ele exploradas. Em nenhum momento podemos caracterizar a abordagem desses autores como piagetiana.

Muitos psicólogos, coǵnitivos no Brasil, por exemplo, evidenciam através dos resultados e modos como conduzem suas pesquisas uma crescente "despiagetinizaçāo" (Nota E). Esta erescente "despiagetinização" pode ser caracterizada por uma crescente consideraçào do ambiente cultural especifico dos sujeitos investigados, consideraçoes estas externas à teoria piagetiana. Os estudos acerca do desenvolvimento cognitivo parecem cada vez mais atentar para o papel desempenhado pelos contextos histórico e cultural em que o individuo opera, adotando além de uma abordagem puramente psicológica, as contribuiẹóes das teorias antropológiea e sociológica.

\section{A Psicologia Cognitiva e áreas alins}

$\mathrm{Na}$ tentativa de compreender o papel da psicologia cognitiva, torna-se relevante analisarmos a relaçào entre estas e outras áreas afins.

A psicologia cognitiva refere-se ao estudo do conhecimento, conseqüentemente envolve a investigaçào de tópicos relevantes à educaçào, tais 
como: aprendizagem, pensamento, raciocinio, formaçào de conceitos, memória, inteligència etc. Desta forma, muitas vezes o exercicio profis sional do psicólogo cognnitivo encontra-se em interrelaçào com o campo de atuaçào de outros profissionais como os da área educacional

Quando o psicólogo escolar adota uma abordagem cognitiva, sua atuaçào pode muitas vezes estar estreitamente relacionada à atuaçào do pedagogo.

Para melhor compreendermos esta interrelaçāo, cabe analisar al. guns aspectos que tèm chamado a atençào do psicólogo escolar. No inicio, a forma de atuaçào do psicólogo escolar se aproximava na prática a do psicólogo clínico, visto que sua atençào voltava-se mais para os aspectos pessoais relacionados ao individuo do que para a aprendizagem propriamente dita. A ènfase de sua atuação recaia fundamentalmente na investigaçāo das relaçōes interpessoais (professor-aluno, alunos entre si) e na busca de soluçōes para problemas pessoais que pudessem surgir no cotidiano escolar ou como conseqüència das relaçóes no contexto escolar ou como conseqüència das relaçỏes no contexto familiar que, de uma ma. neira ou de outra, pudessem afetar a aprendizagem do aluno. Muitas vezes a sala do psicólogo escolar se tornava, em certo sentido, um consultório terapéutico, sobretudo quando as dificuldades apresentadas nào podiam ser encaminhadas para um profissio. nal fora da escola (como freqũente. mente ocorre com a clientela escolar oriunda de clases de baixo nivel sócio-econômico).

Em parte esta ênfase se explica pela orientaça basicamente clínica oferecida pelos curriculos das univer. sidades e pela forma como a psicologia foi introduzida no Brasil, adotando práticas de consultório baseadas no modelo médjco de atendimento individual. Com as mudanças surgi. das na psicologia no Brasil (9) e, es. pecificamente, com o avanço dos es. tudos na área cognitiva e conseqüen. temente a inserçāo de disciplinas relacionadas a esta àrea nos cursos de Psicologia, o foco da atenceăo do psicólogo escolar volta-se para os aspectos relacionados aos processos cognitivos de modo geral.

Desta forma a atençào e atuaçảo do psicóloğo escolar aproximam-se da área de atuaçảo do peda. gogo. Embora tais papéis nảo devam ser confundidos, è evidente que a psicologia cognitiva interessa a ambos, cabendo definir-se mais claramente a contribuiçảo desta na prática de cada um.

Muitas vezes quando o psicólogo cognitivo se ocupa de problemas pedagógicos, a partir dos resultados das próprias pesquisas, tende a eleborar implicaçōes educacionais sem considerar devidamente a contribuição da pedagogia, podendo incorrer no problema de fornecer uṇ enfoque excessivamente psicólogico a tópicos e problemas pedagógicos. Por outro lado, o pedagogo na tentativa de opera. cionalizaçào dos resultados da pesquisa psicológica, em uma perspectiva instrumental e até reducionista, tende a abstrair os dados do contexto teórico onde estes estão inseridos, advogando para si o supremo papel de organizador e elaborador destes a nivel prático, incorrendo por sua vez no problema de dar um enfoque simplis. ta a questōes complexas, generalizando conclusōes e padronizando procedimentos.

Para serem separadas as dificuldades implicitas nesta dicotomia entre teoria e práxis torna-se necessário considerar que ambas as disciplinas, com suas peculiaridades e instâncias, deveriam interagir. Isto nào significa que o pedagogo tenha que ser mais psicólogo ou vice-versa, mas que è preciso reconhecer a existência de competências especializadas que, no entanto, deveriam ser colocadas em intercâmbio para minimizar as distorçōes entre teoria e prática. Nảo se deseja dizer com isso que seja in. viável a transposicảo dos resultados teóricos da pesquisa cognitiva para a práxis pedagógica, mas que esta transposiçào requer trabalho conjunto e interdisciplinar.

\section{A Psicologia Cognitiva no Brasil - em outros paises}

Além da análise da psicologia cognitiva dentro da psicologia como um todo, outras consideraçóes necessitam ser levadas em conta.

Enquanto no Brasil a psicologia cognitiva envolve tanto o estudo das bases do conhecimento quanto o modo como este se desenvolve; em outros paises algumas diferenças podem ser observadas.

Na Inglaterra (Nota C) por exemplo, a psicologia cognitiva está voltada essencialmente para o estudo dos processos e estruturas do conhecimento humano, nảo incluindo o es- tudo do desenvolvimento dessas estruturas e processos. A psicologia cognnitiva na tradiçāo anglo-saxônica relaciona-se ao processamento de informaçào, inteligência artificial; estrutura do pensamento, do raciocinio, da memória etc. $O$ interesse recai sobre a estrutura, processamento e funcionamento dos fenômenos da consciência (12). Por sua vez, a psicologia do desenvolvimento investiga as modificaçōes que sofrem tais estruturas, processos e funcionamento ao longo do desenvolvimento do individua.

Tomemos um fenômeno qualquer, como a percepçảo, por exemplo. Na tradiçảo britânica, enquanto a psicologia cognitiva estaria interessada em investigar as bases da percepcáo humana, em que constitui tal fenòmeno, como ocorre a percepçào sob esta ou aquela circunstancia, o que a influencia, qual o efeito desta sobre outros elementos da consciência ete.; a psicologia do desenvolvi. mento estaria interessada em investigar como tal fenômeno se desenvolve com o passar do tempo, como esta se caracteriza no inicio e no final da infância, que fatores influenciam a per. cepçào infantil e quais aqueles que influenciam a percepçào adulta etc.

Em função desta divisào, a obra de Piaget está consideravelmente mais relacionada à psicologia do desenvolvimento do que à psicologia cognitiva propriamente dita. No Bra. sil, entretanto, a psicologia cognitiva se confunde com a obra de Piaget, pelo menos na visào de leigos e de alguns profissionais. Ainda de acordo com a diferenciaçăo inglesa, a psico. logia do desenvolvimento nāo está re. lacionada apenas à área de estudos dos aspectos cognitivos, mas abran. geria também as áreas social e afetivo-emocional.

No Brasil, a psicologia cognitiva é entendida de maneira bem diferente. Por psicologia cognitiva entende-se tanto o estudo das bases do conhecimento (estrutura, processos e funcionamento) quanto o estudo do desenvolvimento desse conhecimen. to, englobando simultaneamente ambas as perspectivas adotadas na tradiçăo anglo-saxônica.

Apesar das diferenças entre as duas conceppoies de psicologia cog. nitiva entre os dois paises aqui tomados como exemplo para discussảo, é possivel observar-se problemas se. melhantes no que diz respeito ao in. tercâmbio entre as áreas. Na Ingla- 
terra, verifica-se uma falta de entrosamento entre os resultados da área cognitiva e os da área de desenvolvi. mento. No Brasil, a separaçào entre a área cognitiva $\mathrm{e}$ as demais àreas da psicologia gera um isolamento dis. funcional. $\mathrm{E}$ evidente que cada área traz contribuiçóes distintas para o estudo do comportamento, entretanto essas contribuiçóes deveriam ser intercambiáveis. Em nossa perspectiva, os estudos cognitivos nào podem ser reduzidos e localizados a uma área restrita dentro da psicologia, visto que, potencialmente, a obordagem cognitiva pode ser aplicada a qualquer àrea do estudo psicológico do individuo, estando, de uma forma ou de outra, implicita em todas elas. Como recentemente afirmado por Mandler (10), a psicologia cognitiva está inegavelmente a caminho de se tornar área fundamental da psicologia.

\section{Pontos para discussäo}

$O$ primeiro ponto que precisa ser considerado è que a abordagem cognitiva tem sido, nas últimas décadas, a área da psicologia que mais se desenvolveu, não só no Brasil como na Europa e nos Estados Unidos. Surpreendentemente, entretanto, o conhecimento gerado por esta área tem sido setorializado, quer na perspectiva brasileira quer na de outros paises, como a lnglaterra. No Brasil, especificamente, o resultado desta setoria. lizaçào tem criado o isolamento na relaçào da psicologia cognitiva com as demais areas, gerando perdas de ambos os lados.

A superaçào deste impasse requer a diferenciaçao entre competências especializadas e competências setorializadas, que não possuem necessariamente o mesmo significado: enquanto as primeiras sāo legitimas e úteis para o progresso do conhecimento, as segundas, em geral, nào possuem esta sensibilidade interdisciplinar. As competências especiali. zadas possuem uma preocupação sistemática no interior das próprias investigaçóes dos fenómenos, ou seja, procuram considerar o caräter de relativismo e parcialidade teórico-prático da investigaçào própria de uma determinada área. As competências setorializadas produzem e tratam o conhecimento de maneira circular, fechado em si mesmo. A proposta que se coloca nào é que as diversas áreas da ciêneia psicológica percam o seu caráter de especialidade, mas que is. so nảo crie o confinamento e a frag. mentaçào do conhecimento. Os conhecimentos gerados em cada uma dessas áreas precisam ser intercam. biáveis sem perder sua identidade de especializaçảo.

Em busca de explicaçỏes mais adequadas e menos simplistas do comportamento humano, a psicologia cognitiva tem contribuido para a compreensảo de fenómenos de interesse de outras áreas fora da Psicolo. gia. Assim, um segundo ponto que merece reflexào cuidadosa é a ques. tào da transposiçào dos resultados teóricos da pesquisa cognitiva para a práxis em outras áreas, como a edi1. cacional por exemplo. A contribuiçào da psicologia cognitiva para a educaçào é inquestionável, mas essa transposição requer uma atuaçāo interdisciplinar para viabilizar adequadamente a passagem dos resultados da pesquisa psicológica para a práxis pedagógica. Cuidados devem ser tomados com o objetivo de evitar um enfoque reducionista e simplista das teorias e dos resultados da pesquisa cognitiva dentro do contexto escolar, ou um enfoque exclusivamente psicológico a problemas pedagógicos. Um exemplo disso foi a aplicaçào da teoria de Piaget à educaçào, onde a operacionalizaçào incorreu num reducionismo da teoria, abstraindo os dados do contexto teórico maior onde estes estảo inseridos. Outro exemplo mais recente e semelhante é o que vem acontecendo com a aplicaçào dos resultados das pesquisas de Emilia Fer reiro em sala de aula. É evidente que tanto Piaget como Ferreiro apresentam contribuiçòes substanciais à educaçảo, mas a transposição requer trabalho cuidadoso e interdisciplinar.

Um terceiro aspecto refere-se à incompreensào existente entre psicológo cognitivo e piagetiano. De acordo com o exposto, torna-se imprescindivel fazer-se uma distinçāo entre estudos cognitivos e estudos piagetianos. Um primeiro passo para tal é buscar-se uma caracterizaçào do que é a psicologia cognitiva, visto que esta incompreensảo nảo reside apenas entre os nảo-psicólogos, mas dentro da própria psicologia. As disciplinas introdutórias dos cursos de graduaçào poderiam incluir em seus programas reflexóes desta natureza, evitando, assim, que novas geraçỏes de psicólogos incorressem no mesmo tipo de incompreensão. Ao que parece a incompreensão precisa ser esclarecida dentro da própria psicologia.
(A) Em uma perspectiva cognitiva o sientificado de estimulo é bem diferente do significado adotado em uma perspectiva behaviourista. Especificamente neste artigo, partindo-se de uma perspectiva cognitiva, por estimulo entende-se uma situacaio-problema como um todo.

(B) Além do enfoque aietivo e cognitivo colocados em perspectiva neste exemplo hipotético, é evidente que outros fatores oomo os sócio-cul. turais, por exemplo, poderiam ser considera dos, mas, se abordados, dariam mais complexidade ao caso e em nada eselarecerlam o debate em questăo.

(C) As informaçóes aqui apresentadas sobre psicologia cognitiva e do desenvolvimento na tradiça inglesa foram obtidas em entrevista con o Professor Peter E. Bryant do Department of Experimental Psychology da Universidade Oxford, Inglaterra.

(D) Para detalhes acerca da utilizaçào deste método ver Carraher (4)

(E) Para maiores detalhes ver T. Carraher, D. Carreher e A. Schliemann (5).

1. BRUNER,J.S.; GOODNOW,J.J e AUS TIN,G,A Study of Thinking. New York: Willey, 1956

2.CARAMELLI,N, - [ntroduzione. In N.GARA MELLI (Ed.) La Psicologia Cognitioista. Brologna: J] Mulino, 1983.

3. CARAMELLI, N. - Jean Piaget e lo studio det processi congritivi. Roma: Bulzoni, 1954.

4. CARRHER, T.N. . O método ctinices: usando os exames de / Fostet. Rio de Janciro: Editora Vozes, 1983

S. CARKAIIER, T.N., CARRALIER,D.W. O Schljemann, A.D, - Cultura, escola, ldeologia e Cogrniçaso: continuando ulta debate. Caderuos de Pesquisa, 39;3 - ]0, 1986 .

6. FLORES d'ARCAJS, G.B. - Presentazione. In NEISSER V. La psiconiogia congnitivista. Milano: Aldo Mlartello - Gumbi Pditore, 1976.

7.HUGHES, $M$, $\mathrm{C}$ DONALDSON, M; - The use of hiding games for studying the eco-ordination of viewpoints. Edustational Revicw, 31: 133.140, 1979

\$. LIGHT, P.H.; BUCKINGIHAM, N. E ROBBINS, A. H. - The conservation task as an interactional secting. British Jounal of Educational Psychokiggy, 49: 304-310, 1979.

9. MALSEEIRO, D.P. E NADER, R.M. - Contrihuicào a uma andalise da psicologia. Pytcologia Ciênctí e Profissấo, 2(7): 9.13, 1987.

10. MANDLEK, G. - Cognitiec psychology: an essay in cosnitive science. Hillsdale, N.J. Lamrence Erlbaum, 1985.

11. MeGARRIGLE,J. E DONALOSON,M. Conservation accidents, Cognition, 3 : $341-350,1974 / 1975$

12. NEISSER,V. - Cognitive Psycicology. New Jersey: Prentice-hall, 1967

13. PARISI,D., CASTEL FRANCH!,C. e BENIG $\mathrm{NI}, \mathrm{L}$. - Otto punti per una discussione sulla Psieokodia Suciale. Simposio sti Problemi Az tuali di Metodo e di Ricerca in Psicologia So ciale, Bologna, 1975

14. ROAZZI,A, - Impliercioes metodológieas na pesquisa transcultural: a influência do cont texto social em tarefas lógicas. Arquívos Brasileiros de Psicologia,38( 3): 71-91, 1986.

15. ROAZZI, A. e DLAS,M.G.B. - A influência da experiência sóciocultural em erianças inglestess. Dados experimentais e exploracóes teóticas ns tarefa de conservaçâ. Arcutvos Brasileiros de Psicologix, 2: 39.56, 1987

16. ROSE,SA e BLANK,M - The potency of context in children's eognition: an illustration from conservation. Child Development, 45: 499-502, 1974. 